Mini Review

\section{Bifid Mandibular Canals: A case report and mini review}

\author{
Sourav Sarkar ${ }^{1 *}$ and Saini Mondal ${ }^{2}$ \\ 'Department of Dentistry, Sri Ramkrishna Institute of Medical Sciences \& Sanaka Hospitals, India \\ ${ }^{2}$ Senior Lecturer, Department of Oral Pathology, Awadh Dental College \& Hospital, Jamshedpur, India
}

\section{Introduction}

The presence of bifid mandibu $\neg$ lar canals is an unusual but not rare occurrence. The mandibular canal containing the inferior alveolar artery, vein, and nerve, originates from the mandibular foramen and terminates at mental foramen [1-4]. In radiology, mandibular canal's appearance has been described as "a radiolucent dark ribbon between two white lines" [5]. White and Pharoah defined it as "dark linear shadow with thin radiopaque superior and inferior borders cast by the lamella of bone that bounds the canal" [6]. Understanding of its anatomic variations is very important due to its clinical implications in various oral and maxillofacial treatments like removal of wisdom teeth [7], mandibular implant placement [8], in bilateral sagittal split osteotomy procedures and during fixation of mandibular fractures. Presence of bifid or multiple mandibular canals forces the clinician to change the treatment plan. Ignoring this variation can cause several complications intra or postoperatively or even result in failure of treatment. For instance a bifid canal if ignored during surgical removal of third molar or dental implant placement can cause prolonged pain even after administering local anesthesia and also severe bleeding if the accessory canal is encroached [2].

Bifid mandibular canals may originate from the mandibular foramen independently or might bifurcate from a single canal during its course inside the mandible [8]. Bifid mandibular canals have been by classified by multiple authors according to anatomical location and configuration, on panoramic radiographs and computerized tomography. According to Carter and Keen [1], inferior alveolar nerve can be arranged as- Type I: single large bony canal, Type II: canal is lower down in the mandible and Type III: canal separates posteriorly into two large branches.

Nortje, et al. [9] gave patterns of duplication as- Type I: duplicate canals from a single mandibular foramen which can be of same size/lower canal smaller/upper canal smaller. Type II: short upper canal up to the second molar areas. Type III: two canals from separate foramina, joining at molar area and Type IV: supplemental canals joining the main canals in the retromolar areas. This report describes a case of a bilateral

\author{
More Information \\ *Address for Correspondence: Sourav Sarkar, \\ Department of Dentistry, Sri Ramkrishna Institute \\ of Medical Sciences and Sanaka Hospitals, \\ Durgapur, West Bengal, 713212, India, \\ Tel: 08670303439 ; \\ Email: sourav_allen9927@yahoo.in \\ Submitted: 27 March 2020 \\ Approved: 02 April 2020 \\ Published: 03 April 2020 \\ How to cite this article: Sarkar S, Mondal S. \\ Bifid Mandibular Canals: A case report and mini \\ review. J Clin Adv Dent. 2020; 4: 006-008. \\ DOI: 10.29328/journal.jcad.1001015 \\ Copyright: (c) 2020 Sarkar S, et al. This is an open \\ access article distributed under the Creative \\ Commons Attribution License, which permits \\ unrestricted use, distribution, and reproduction \\ in any medium, provided the original work is \\ properly cited. \\ A) Check for updates \\ 0 OPEn Access
}

Bifid Mandibular Canal suspected by a panoramic radiograph and confirmed by a CBCT prior to a dental treatment.

\section{Case Report}

A 43-year-old female patient reported to the Department of Dentistry, with a complaint of missing teeth for 6 months and wanted to get them replaced with dental implant rehabilitation. Intraoral examination revealed multiple missing teeth. The patient mentioned a history of difficulty in anesthetizing her lower left first molar during extraction by her previous dentist. The patient was advised for an orthopantomogram for further evaluation. Orthopantomogram revealed an edentulous area at 36 region and also the existence of bilateral bifid mandibular canal was noticed. In her left jaw two separate canals with well-corticated wall could be seen.

A CBCT was requested for further assessment. The axial and coronal cross sections revealed two mandibular canals ending into one single mental foramen. A single canal originated from the mandibular foramen, passes along the ramus and angle region and bifurcates into two branches below the third molar area into upper and lower branches. In the right side the lowest branch of the canal showed no relation with the apical part of the roots of the molars whereas the upper branch was positioned lingual to the roots a sign of high risk for nerve damage. The upper branch terminates at the edentulous region of the first molar into the bony trabaculae while the lower branch continues to the mental foramen bilaterally. 
The lower branch extends post mental foramen as the incisive nerve. The patient was informed about the reason of previous difficult local anesthesia due to the presence of this anatomical aberration (Figure 1).
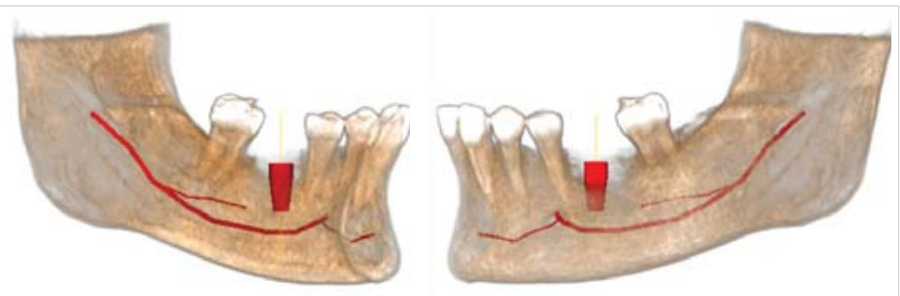

Figure 1: Presence of bifid inferior alveolar nerve bilaterally, dividing from the main trunk below the lower second molar region.

\section{Discussion}

It is common to misinterpret a bifid mandibular canal in an orthopantomogram due to superimposition of various anatomical structures and inadequate positioning of the patient [10]. Although the mandibular canal is considered as a single bilateral structure, there are several reports in the literature which gives evidence of a second or even a third accessory mandibular canal [11-14,23-26]. Pioneer studies reported the incidence of bifid mandibular canals as $1 \%$. $[9,10]$ These study models evaluated the presence of bifid mandibular canals using orthopantomogram. However, with the advancement in dental imaging with the introduction of cone beam CT, recent studies pointed to a broad variation of the incidence, ranging from $0.09 \%$ to $36 \%[11,12,24]$. This wide variation is mainly due to differences in the sample size and type of radiography incorporated for each study. One of the meta-analysis revealed that studies carried out using panoramic images showed a relatively lower incidence than the studies with computed tomography images $[18,24,26]$.

Chavez-Lomeli, et al. gave a theory for this variation in mandibular canal anatomy. They suggested that during embryologic development of the mandible, the branches of the mandibular nerve innervating the three groups of mandibular teeth fuse together and form a single unified nerve in a single mandibular canal. Thus, lack of fusion of these nerves results in the existence of accessory canals [19]. In 1973, Kiersch and Jordan suggested the cause of misinterpretation of a single canal as a bifid canal in a panoramic radiograph. They observed that the osteocondensation image produced by the insertion of the mylohyoid muscle into the internal mandibular surface mimics a bifid mandibular canal.[16,17,20] However, analysis of CBCT images would not result in such interpretation as the bifurcation can be visualized in three different spatial planes. Bifid mandibular canals have showed higher prevalence in females $[10,14,15]$. However, the gender differences could be more related to the population observed rather than to the type of radiographic examination.

Presence of a bifid mandibular canal may have various important clinical implications [4,15,18,27,28]. Performing a third molar surgery in such cases may cause excessive bleeding or numbness, if the accessory canal is not taken into consideration [10]. Inadequate anesthesia, complications in procedures such as endodontics, dental implants and mandibular osteotomy, are the other problems if mandibular canal variations are not recognized [22].

\section{Conclusion}

The presence of bifid mandibu-lar canals is an unusual occurrence. Adequate knowledge of both the anatomy and the anatomical variations of the inferior alveolar canal are essential to prevent any complications during mandibular dental procedures. CBCT images proves to be the most preferable tool for investigating, identifying and confirming such variations of the canal.

\section{References}

1. Carter RB, Keen EN. The intramandibular course of the inferior alveolar nerve. J Anat. 1971; 108: 433-440.

PubMed: https://www.ncbi.nlm.nih.gov/pubmed/5575310

2. Moiseiwitsch JRD. Position of the mental foramen in a North American, white population. Oral Surg Oral Med Oral Pathol Oral Radiol Endod. 1998; 85: 457-460.

PubMed: https://www.ncbi.nlm.nih.gov/pubmed/9574957

3. Wadu SG, Penhall B, Towsend GC. Morphological variability of the human inferior alveolar nerve. Clin Anat. 1997; 10: 82-87.

PubMed: https://www.ncbi.nlm.nih.gov/pubmed/9058013

4. Nikzad S, Azari A, Sabouri S. Double mandibular foramina and canal: report a case with interactive CT-based planning software. Iran J Radiol. 2008; 5: 83-86.

5. Worth HM. Normal radiographic appearances of the teeth and jaws and variations within the normal. Principles and Practice of Oral Radiologic Interpretation. Chicago, IL: Year Book Medical Publishers, Inc.; 1963; 15-79.

6. White SC, Pharoah MJ, editors. Oral Radiology, Principles and Interpretation. 5th ed. St. Louis, Missouri: Elsevier; 2006; 184.

7. Ghaeminia H, Meijer GJ, Soehardi A, Borstlap WA, Mulder J, et al. Position of the impacted third molar in relation to the mandibular canal. Diagnostic accuracy of cone beam computed tomography compared with panoramic radiography. Int J Oral Maxillofac Surg. 2009; 38: 964-971. PubMed: https://www.ncbi.nlm.nih.gov/pubmed/19640685

8. Worthington P. Injury to the inferior alveolar nerve during implant placement: a formula for protection of the patient and clinician. Int $\mathrm{J}$ Oral Maxillofac Implants. 2004; $19: 731-734$.

PubMed: https://www.ncbi.nlm.nih.gov/pubmed/15508990

9. Nortje CJ, Farmen AG, Grotepass FW. Variations in the normal anatomy of the inferior dental (mandibular) canal: a retrospective study of panoramic radiographs from 3612 routine dental patients. $\mathrm{Br} \mathrm{J}$ Oral Surg. 1977; 15: 55-63.

PubMed: https://www.ncbi.nlm.nih.gov/pubmed/268217

10. Langlais RP, Broadus R, Glass BJ. Bifid mandibular canals in panoramic radiographs. J Am Dent Assoc. 1985; 110: 923-926.

PubMed: https://www.ncbi.nlm.nih.gov/pubmed/3860553

11. Devito KL, Tamburús JR. Anatomy of the mandibular canal: radiological classification of its variations. Rev Assoc Paul Cir Dent. 2001; 55: 261 . 236. 
12. Rossi PM, Brücker MR, Rockenbach MIB. Bifid mandibular canals: panoramic radiographic analysis. Rev Cienc Med. 2009; 18: 99-104.

13. Rouas $P$, Nancy J, Bar D. Identification of double mandibular canals: literature review and three case report with CT scans and cone beam CT. Dentomaxillofac Radiol. 2007; 36: 3438.

PubMed: https://www.ncbi.nlm.nih.gov/pubmed/17329586

14. Naitoh $M$, Hiraiva $Y$, Aimiya $H$, Ariji E. Observation of bifid mandibular canal using cone beam computerized tomography. Int J Oral Maxillofac Implants. 2009; 24: 155-159.

PubMed: https://www.ncbi.nlm.nih.gov/pubmed/19344041

15. Kuribayashi A, Watanabe $H$, Imaizumi A, Tantanapornkul W, Katakam $\mathrm{K}$, et al. Bifid mandibular canals: cone beam computed tomography evaluation. Dentomaxillofac Radiol. 2010; 39: 235-239.

PubMed: https://www.ncbi.nlm.nih.gov/pubmed/20395465s

16. Fu E, Peng M, Chiang CY, Tu HP, Lin YS, et al. Bifid mandibular canals and the factors associated with their presence: a medical computed tomography evaluation in a Taiwanese population. Clin Oral Implants Res. 2014; 25; e64-e64.

PubMed: https://www.ncbi.nlm.nih.gov/pubmed/23130919

17. de Oliveira-Santos C, Souza PH, De Azambuja Berti-Couto SA, Stinkens $\mathrm{L}$, Moyaert K, et al. Assessment of variations of the mandibular canal through cone beam computed tomography. Clin Oral Investig. 2012 16: 387-393

PubMed: https://www.ncbi.nlm.nih.gov/pubmed/21448636

18. Sanchis JM, Peñarrocha M, Soler F. Bifid mandibular canal. J Oral Maxillofac Surg. 2003; 61: 422-424.

PubMed: https://www.ncbi.nlm.nih.gov/pubmed/12684957
19. Kim MS, Yoon SJ, Park HW, Kang JH, Yang SY, et al. A false presence of bifid mandibular canals in panoramic radiographs. Dentomaxillofac Radiol. 2011; 40: 434-438.

PubMed: https://www.ncbi.nlm.nih.gov/pubmed/21960401

20. Arensburg B, Nathan $\mathrm{H}$. Anatomical observation of the mylohyoid groove, and the course of the mylohyoid nerve and vessels. J Oral Surg. 1979 Feb;37(2):93-6.

PubMed: https://www.ncbi.nlm.nih.gov/pubmed/105109

21. Xie Q, Wolf J, Soikkonen K, Ainamo A. Height of mandibular basal bone in dentate and edentulous subjects. Acta Odontol Scand. 1996; 54: 379-383.

PubMed: https://www.ncbi.nlm.nih.gov/pubmed/8997437

22. Auluck A, Pai KM, Shetty C. Pseudo bifid mandibular canal. Dentomaxillofac Radiol. 2005; 34: 387-388.

PubMed: https://www.ncbi.nlm.nih.gov/pubmed/16227485

23. Bogdan S, Pataky L, Barabas J, Nemeth Z, Huszar T, et al. Atypical courses of the mandibular canal: comparative examination of dry mandibles and x-ray. J Craniofac Surg. 2006; 17: 487-491. PubMed: https://www.ncbi.nlm.nih.gov/pubmed/16770186

24. Wadhawani $P$, Mathur RM, Kohli M, Sahu R. Mandibular canal variant: a case report. J Oral Pathol Med. 2008; 37: 122-124. PubMed: https://www.ncbi.nlm.nih.gov/pubmed/18197857

25. Fukami K, Shiozaki K, Mishima A, Kuribayashi A, Hamada $Y$, et al. Bifid mandibular canal: confirmation of limited cone beam computed tomography findings by gross anatomical and histological investigations. Dentomaxillofac Radiol. 2012; 41: 460-465. PubMed: https://www.ncbi.nlm.nih.gov/pmc/articles/PMC3520398/ 